\title{
Epidemiology of obesity in developing countries: challenges and prevention
}

\author{
Mohammed Ellulu ${ }^{1 *}$, Yehia Abed ${ }^{2}$, Asmah Rahmat ${ }^{1}$, Yazan Ranneh ${ }^{1}$ and Faisal Ali ${ }^{1}$ \\ *Correspondence: mohdsubhilulu@gmail.com

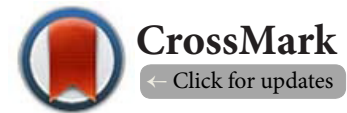 \\ 'Department of Nutrition and Dietetics, Faculty of Medicine and Health Sciences, \\ University Putra Malaysia, Malaysia. \\ ${ }^{2}$ Faculty of Public Health, Al Quds University of Gaza, Palestine.
}

\begin{abstract}
Almost all countries are facing obesity endemic, although great variation exists between and within countries. Sedentary lifestyle and high fat (high caloric) diet have increased globally as a result of industrial, urban and mechanic changes of developing countries. Improved economic status promotes the obesity and metabolic syndrome in all age groups particularly young adults. Developing counties became in desperate need for establishing new polices and strategies within regulated and managed programs; in order to encounter factors of highly spread malnutrition displayed by obesity and its consequences like diabetes, CVD and metabolic syndrome. Developed and developing countries have studied the obesity prevalence, showing important statistics as the obesity hugely escalated in all population groups. Obesity and its related non-communicable diseases (NCDs) have new pandemic facts that force the World Health Organization (WHO) to deal with.WHO noticed that obesity and NCDs will affect majorly the developing countries, and the expected numbers of new cases within the next 2 decades will exceed hundreds of millions. This review, discusses the epidemiology of obesity, lifestyle and nutritional transitions, determinants, social and economic impacts, and possible solutions for prevention of obesity in developing countries.
\end{abstract}

Keywords: Epidemiology, obesity, prevention, non-communicable diseases

\section{Introduction}

Obesity is defined as abnormal or excessive fat accumulation that may impair health. It becomes the most glaring outward sign of the changing face of malnutrition in developing countries; increase the chances of a person falling prey to the other noncommunicable diseases. It is measured through the Body Mass Index (BMI), a simple index of weight-height relationship that indicates amount of body fat used to classify overweight and obesity in adults [1]. The body mass index (BMI), calculated as weight in $(\mathrm{kg})$ divided by height in $(\mathrm{m})$ squared [2]. Other indices, such as waist and hip circumferences, measure different aspects of body composition and fat distribution which have independent and often opposite effects on cardiovascular disease risk factors [3]. Waist circumference is a relatively simple and convenient measure and can be used to assess the quantity of abdominal fat. Hip measurements provide additional valuable information about gluteofemoral muscle mass and bone structure [4]; hip circumference is negatively associated with health outcomes in women [5]. The waistto-hip ratio (WHR) may therefore be a useful measure, since it also includes the accumulation of fat on the hips; such an accumulation may be beneficial for health [3].

If an individual has a BMI from 25 to less than 30, he or she is overweight. Having a BMI of 30 or more means an individual is obese. The risk of chronic diseases have increased as BMI has escalated resulting in obesity. These diseases include cardiovascular diseases, diabetes, musculoskeletal disorders, cancer, and premature death.

Changes in dietary and physical activity patterns are often the result of environmental and societal changes associated with development and lack of supportive policies in sectors such as health, agriculture, transport, urban planning, environment, food processing, distribution, marketing and education.

Obesity rates in Western Africa are estimated to be $10 \%$. Rates of obesity among women are three times those found in men. In urban West Africa rates of obesity have more than doubled in the last 15 years [6].

According to the WHO estimates, the undernourished population in the world has declined and is roughly around 1.2 billion, whereas the over nourished population has increased to 1.2 billion [7]. WHO data also show that, globally, there are more than 1 billion adults overweight and 300 million obese people. The problem of obesity is increasing in the developing world with more than 115 million people suffering from obesity related problems. Obesity rates have increased 3-fold or more since 1980 in Middle East, the Pacific Islands, Australasia, and China $[8,9]$.

Whereas the prevalence of obesity may not be high in many areas in some developing countries, like China, Japan, and certain African nations, it is extremely high (75\%) in other 
Ellulu et al. Global Epidemic Obesity 2014,

countries like urban Samoa. Even in low-prevalence countries, the prevalence is significantly high $(20 \%)$ in urban areas $(23 \%)$ [8-10], (Table 1) will provide some statistics about overweight and obesity among adults from different countries. Recently, application of lower cutoff of body mass index (BMI) (Asian criteria of overweight: $23-25 \mathrm{~kg} / \mathrm{m}^{2}$ and obesity: $>25 \mathrm{~kg} / \mathrm{m}^{2}$ ) $[8,9]$ has led to increase in prevalence figures in several Asian countries $[11,12]$. Overall, it appears that overweight and obesity may already be more than underweight and undernutrition in many developing nations. Rural-urban differences in obesity, the metabolic syndrome, and T2DM is seen in most developing countries [13].

Furthermore, whereas overweight and obesity in underprivileged people in developed countries is substantial, in developing countries rural-based people are mostly lean and have low prevalence of T2DM and CVD. However, underprivileged people residing in urban areas (mostly rural to urban migrants) show increasing prevalence of overweight/ obesity and other cardiovascular risk factors [14].

Similar to adults, the prevalence of overweight and obesity and overweight in children in developing countries shows an increasing trend. This is a serious challenge because

Table 1. Selected statistics on overweight and obesity from most recent national prevalence surveys in adults.

\begin{tabular}{|c|c|c|c|c|c|c|c|c|}
\hline \multirow[b]{2}{*}{ Country } & \multirow[b]{2}{*}{ Survey date } & \multirow[b]{2}{*}{ Age range } & \multicolumn{3}{|c|}{ Overweight $\left(\% \mathrm{BMI}>25 \mathrm{~kg} / \mathrm{m}^{2}\right)$} & \multicolumn{3}{|c|}{ Obese $\left(\% \mathrm{BMI}>30 \mathrm{~kg} / \mathrm{m}^{2}\right)$} \\
\hline & & & Male & Female & Both & Male & Female & Both \\
\hline \multicolumn{9}{|l|}{ Europe } \\
\hline Germany & 1998 & $18-79$ & 67 & 54 & 60 & 19 & 22 & 21 \\
\hline Ireland & 1997-99 & $18-64$ & 66 & 48 & 57 & 20 & 16 & 18 \\
\hline Latvia & 1997 & $19-64$ & 51 & 50 & 50 & 10 & 17 & 14 \\
\hline Norway & 1994 & $16-79$ & 42 & 26 & 34 & 5 & 6 & 5 \\
\hline Sweden & 1996-97 & $16-84$ & 46 & 34 & 40 & 7 & 7 & 7 \\
\hline \multicolumn{9}{|l|}{ North America } \\
\hline Canada & $2000-01$ & $20-64$ & 56 & 39 & 47 & 16 & 14 & 15 \\
\hline USA & 1999-2002 & $16+$ & 66 & 60 & 63 & 26 & 32 & 28 \\
\hline \multicolumn{9}{|l|}{ Asia } \\
\hline China & 1990-2000 & $20+$ & 22 & 26 & 25 & 2 & 4 & 3 \\
\hline India & 1998 & $18+$ & 4 & 4 & 4 & 0.3 & 0.5 & 0.5 \\
\hline Japan & 2001 & $15+$ & 27 & 21 & 23 & 3 & 3 & 3 \\
\hline Philippines & 1998 & $20+$ & 17 & 23 & 20 & 2 & 4 & 3 \\
\hline Singapore & 1998 & $18-69$ & 34 & 27 & 30 & 5 & 7 & 6 \\
\hline \multicolumn{9}{|l|}{ Pacific Islands } \\
\hline Cook Islands & 1998 & $17+$ & 77 & 81 & 78 & 41 & 50 & 43 \\
\hline Fiji & 1993 & $18+$ & 32 & 50 & 42 & 7 & 21 & 14 \\
\hline French Polynesia & 1995 & $16+$ & 75 & 73 & 74 & 36 & 44 & 41 \\
\hline Nauru & 1994 & $25-69$ & - & - & - & 80 & 79 & 79 \\
\hline Vanuatu & 1998 & $20+$ & 46 & 52 & 49 & 12 & 20 & 16 \\
\hline \multicolumn{9}{|l|}{ Middle East } \\
\hline Bahrain & 1998-99 & $19+$ & 60 & 62 & 61 & 23 & 34 & 29 \\
\hline Egypt & 1998-99 & $18-60$ & 49 & 71 & 62 & 13 & 33 & 25 \\
\hline Iran & 1999 & $15+$ & 29 & 39 & 34 & 6 & 14 & 10 \\
\hline Saudi Arabia & 1995 & $18+$ & 40 & 46 & 43 & 13 & 20 & 17 \\
\hline \multicolumn{9}{|l|}{ Africa } \\
\hline Ghana & 1987-89 & $20-65$ & 5 & 18 & 11 & 1 & 6 & 3 \\
\hline Lesotho & 1993 & $20-65$ & - & 50 & - & - & 23 & - \\
\hline Morocco & 1998-99 & $18+$ & 25 & 45 & 36 & 4 & 16 & 10 \\
\hline South Africa & 1998 & $15+$ & 29 & 56 & 45 & 9 & 30 & 21 \\
\hline
\end{tabular}

Source: Int J Epidemiol February 2006 vol. 35 no. 1 93-99. The emerging epidemic of obesity in developing countries. 
malnutrition and stunted growth are often seen to coexist in children, and eliminating undernutrition without increase in obesity is required [15]. Since 1986, several surveys in preschool children show increasing obesity in most countries in Latin America and the Caribbean, along with the Middle East and North Africa, which is comparable with prevalence rates of childhood obesity seen in the United States [15]. Similar trends have also been observed in India, Mexico, Nigeria, and Tunisia over the past 2 decades [16]. The prevalence of obesity among 5 to 12 years old children in Thailand increased from 12.2 to $15.6 \%$ over a period of 2 years $[\mathbf{8}, 9]$. Increase in the prevalence of overweight among older children and adolescents has been seen as well; from 4.1 to $13.9 \%$ between 1975 and 1997 in Brazil, from 6.4 to $7.7 \%$ between 1991 and 1997 in China, and from 16 to 24\% between 2002 to 2007 in New Delhi, India $[17,18]$. Furthermore, overweight was more common in urban areas vs. rural areas, privately funded schools vs. government funded schools, girls vs. boys in India [17].

The Middle East, including the Arabian Peninsula, Eastern Mediterranean, Turkey, Iran, and North Africa, are no exception to the worldwide increase in obesity. Subsequently, some call this trend the New World Syndrome [18]. Blood pressure and heart diseases sound to be more than twice among overweight children than normal weight ones. The adult onset diabetes could be predicted and linked to childhood obesity, imposing them at risk of a wide range disorders like blindness, nerve damaging, kidney disease and cardiovascular diseases.

\section{Review}

\section{Global burden-'The double burden of disease'}

For thousands of years obesity was rarely seen [19]. It was not until the 20th century that it became common, so much so that in 1997 the World Health Organization (WHO) formally recognized obesity as a global epidemic [20]. As of 2008, The World Health Organization claimed that 1.5 billion adults, 20 and older, were overweight and of these over 200 million men and nearly 300 million women were obese [21]. The rate of obesity also increases with age at least up to 50 or 60 years old [22]. Once considered a problem only of high-income countries, obesity rates are rising worldwide. The only remaining region of the world where obesity is not common is sub-Saharan Africa [23].

Overweight and obesity are the fifth leading risk for global deaths. At least 2.8 million adults die each year as a result of being overweight or obese. In addition, $44 \%$ of the diabetes burden, $23 \%$ of the ischaemic heart disease burden and between $7 \%$ and $41 \%$ of certain cancer burdens are attributable to overweight and obesity. Overweight children are more than twice as likely to have high blood pressure or heart disease as children of normal weight. The second type of diabetes is the form which occurs in adults, and visceral obesity may be a predisposing factor in children for the development of a second type of diabetes, but when they become adults and after that may develop the typical complications for diabetes type 2 like cardiovascular, renal and retinal complications. Some WHO global estimates from 2008 follow $[\mathbf{8 , 9}, \mathbf{2 1}]$.

1) 1.5 billion adults, 20 and older, were overweight.

2) Of these 1.5 billion overweight adults, over 200 million men and nearly 300 million women were obese.

3) Overall, more than one in ten of the world's adult population was obese.

In 2010, around 43 million children under five were overweight. Once considered a high-income country problem, overweight and obesity are now on the rise in low- and middle-income countries, particularly in urban settings. Close to 35 million overweight children are living in developing countries and 8 million in developed countries.

Obesity related medical problems affect very huge number which exceed 115 million individuals according to WHO in developing countries. These disorders according to WHO will be the number one of death cause among needy population by 2030 [21].

The public health agenda of WHO put the obesity in the apex as it avoidable risk factors for many disorders according to reports deal with diet, nutrition and prevention of chronic diseases $[\mathbf{8}, \mathbf{9}, \mathbf{2 0}, \mathbf{2 1}]$. The followed Global Strategy on diet, physical activity and health explored that more than $65 \%$ of all death cases related to NCDs especially in poor countries and it may be rise. As the mortality rate in these countries elevated and associated with unsuitable health services; the death from NCDs among low ages will escalated.

The recent up growth of NCDs as a threatening of health; still compete with unlimited infectious diseases and childhood malnutrition which termed "The Double Burden of Disease". Together with AIDS, and reappearance of past disease due to drug resistance as TB and malaria, this envelope will worsen the health status in developing countries. In 2005, WHO has estimated the China expenses to deal with heart disease, stroke and diabetes with the time period $2005-15$ by $\$ 556$ billion [24]. The likelihood of crippling the obesity epidemic within the expected future appear remote specially in societies that have struggled for decades to escape from the exhausting monotony and the economic diets and living conditions of a survival livelihood. Paradoxically further economic development probably will be one of the best ways out of the problem by carrying populations beyond the poverty-obesity links described by Stunkard [25]. In the meanwhile public education campaigns warning of the health consequences of very high levels of body fat could be the most that many countries can produce. Unwillingly, it has to be declared that the medium-term outlook is, therefore, frustrated if we are looking for miracles. However, gradual progress can be achieved against the two leading avoidable risk factors for chronic disease, namely smoking and obesity. A new series on chronic diseases in The Lancet directs with a call to set the mild target of a $2 \%$ per annum decrease in deaths from chronic diseases worldwide [26,27]. This would avoid 36 million deaths tolls by 2015 of which the great majority would be in 
Ellulu et al. Global Epidemic Obesity 2014,

low- and middle-income countries.

\section{Cause consequence}

The imbalance increment of energy intake more than energy expenditure is considered the fundamental cause of obesity and overweight. Globally, there has been:

1) The intake of high dense energy foods which involve fats, sugars and salt at the time they poor of essential micronutrients have been increased.

2) Sedentary lifestyle because of forms of work, increased urbanization and changed modes of transportation which mean a little physical action.

BMI has been raised due to overweight and obesity that is the major cause for many of non-communicable disease such as [21,28-30]:

1) Cardiovascular diseases (especially stroke and heart failure) were considered the major cause of death in 2008.

2) Diabetes (especially type 2 ).

3) Osteoarthritis, which is main musculoskeletal degenerative disorder affects joints.

4) Cancers like prostate, colon and breast.

\section{Economic cost of obesity}

Thompson [31] suggested the worse of obesity by decreased life quality, increased health care costs and absenteeism. There is an exponential rising of costs due to CVD and diabetes type 2 as result of obesity, along with associated complications. These costs become unmanageable by health budget in poor countries and aligned health initiatives (more toward communicable diseases).

Popkin et al., [32] reviewed the costs of diet related NCDs as CVD, diabetes type 2 and hypertension, the findings indicated that India is less advantageous position compared with China. According to Popkin team, the mortality of diet related NCDs is predictable to increase to $43.3 \%$ of all deaths in India. As the NCDs escalated the cost also increased. The cost in 1995 was $\$ 3.4$ billion, about $1.1 \%$ of the GDP of India. In 2000, in Latin America and the Caribbean, the direct and indirect costs of diabetes (as result from obesity) were about $\$ 65.2$ billion according to WHO estimation [33].

In the Pacific Islands, about $\$ 1.95$ million is a cost of obesity induced diabetes in Tonga while $\$ 13.6$ million in Fiji, taking about 60 and $39 \%$ of health budgets, respectively [34]. In 2003, the mainland China expended nearly 21.1 billion Yuans (about $\$ 2.74$ billion) in medical costs of overweight and obesity, counting nearly $25.5 \%$ of the total costs of medical care of chronic diseases and nearly $3.7 \%$ of national total medical costs [35]. The expenses of obesity alone in China in 2000 were about $\$ 50$ billion and expected to rise to about $\% 112$ billion by 2025 [36].

\section{Challenges and prevention}

There are two interventions for preventing weight gain; the first one is selective which directed to whom above average risk of developing obesity, and the second one is the targeted prevention which strongly directed to population of high risk. The strategies of interventions should be sensitive to the culture, un-exhausting cost, adapted to the local habits and practice, send simple messages in line of planned health budgets, and widespread unawareness and illiteracy in developing countries. The strategies should gather various stakeholders that involve government, physicians, nutritionist, schools and NGOs. Furthermore, the sub-sectional harmony of different governmental departments as health, nutrition, legal, agricultural and education is important. Clearly, the primary care based programs in developing countries still underuse. The prevention of obesity in infants and young should be considered of high priority. The main preventive strategies are:

1) Promoting excessive breast feeding.

2) Instructing mothers to accept their child's ability to regulate energy intake rather than eating until the plate is empty.

3) Avoiding use of added sugar and starches when feeding formulas.

4) Assuring the appropriate micronutrient intake needed to promote optimal linear growth.

For children and adolescents, prevention of obesity implies the need to:

1) Promote an active lifestyle.

2) Limit television viewing, and use of electronic devices such ascomputer games.

3) Promote fruits and vegetables intake. Restrict the intake of energy dense, micronutrients poor foods (e.g., packaged snacks).

4) Restrict the intake of sugar-sweetened soft drinks. In developing counties, the stunted population groups should have attention in order to avoid overfeeding. The programs of nutrition have established to prevent or at least to control under nutrition need, which is to access stature in conjunction with weight to prevent providing an excess of energy to children of low weight for age but normal weight for height. In countries with economic transition status, the population habits become more sedentary with accessibility to high dense calorie foods; there is a need to save the healthy components of traditional diets (e.g., high intake of vegetable, fruits and NSP). Educational courses to mothers and low socioeconomic status communities about food insecure should provide the mean of good health is not overweight or obesity.

\section{Conclusion}

In past few decades in developing countries, obesity has a rapid increment leading to increased risk of CVD and its morbidity and mortality consequences. Because of malnutrition even under-or overnutrition are seen together in developing countries, the double burden of diseases makes the condition more difficult. Multiple factors take the responsibility for increasing the NCDs are rapidly transition of nutrition, sedentary lifestyle and occupation, and ruralto- 
urban migration. Interventions of health policies and strategies have established to prevent or even reduce the mortality and morbidity; need to be addressed for both adults and children. Interventions should be objected for elevating health literacy and increasing the physical activity along with healthier food patterns.

\section{List of abbreviations}

WHO: World Health Organization.

CVD: Cardiovascular diseases.

NCDs: Non-Communicable diseases.

BMI: Body Mass Index.

GDP: Growth Domestic Population.

\section{Competing interests}

The authors declare that they have no competing interests.

Authors' contributions

\begin{tabular}{|l|c|c|c|c|c|}
\hline Authors' contributions & ME & YA & AR & YR & FA \\
\hline Research concept and design & $\checkmark$ & -- & -- & $\checkmark$ & -- \\
\hline Collection and/or assembly of data & $\checkmark$ & -- & -- & $\checkmark$ & -- \\
\hline Data analysis and interpretation & -- & -- & -- & -- & $\checkmark$ \\
\hline Writing the article & $\checkmark$ & -- & -- & $\checkmark$ & -- \\
\hline Critical revision of the article & -- & $\checkmark$ & $\checkmark$ & -- & -- \\
\hline Final approval of article & -- & $\checkmark$ & $\checkmark$ & -- & -- \\
\hline Statistical analysis & -- & -- & -- & -- & $\checkmark$ \\
\hline
\end{tabular}

\section{Acknowledgement}

The authors would like to thank the Arab Medical Union for partially financial supports, and they would like to acknowledge Faculty of Medicine and Health Sciences- University Putra Malaysia, and Faculty of Public Health- Alquds University of Palestine for the use of library.

\section{Publication history}

Editor: Analia Tomova, Medical University, Bulgaria.

Received: 23-Jan-2014 Final Revised: 27-Feb-2014

Accepted: 10-Mar-2014 Published: 26-Mar-2014

\section{References}

1. Chris Burslem, October. The Changing Face of Malnutrition. IFPRI Forum, International Food Policy Research Institute: Washington, D.C. 2004. I $\underline{\text { Pdf }}$

2. Katz DL, O'Connell M, Yeh MC, Nawaz H, Njike V, Anderson LM, Cory S and Dietz W. Public health strategies for preventing and controlling overweight and obesity in school and worksite settings: a report on recommendations of the Task Force on Community Preventive Services. MMWR Recomm Rep. 2005; 54:1-12. | Article | PubMed

3. Avenell A, Broom J, Brown TJ, Poobalan A, Aucott L, Stearns SC, Smith WC, Jung RT, Campbell MK and Grant AM. Systematic review of the longterm effects and economic consequences of treatments for obesity and implications for health improvement. Health Technol Assess. 2004; 8:iii-iv, 1-182. | PubMed Abstract | PubMed Full Text

4. Flynn MA, McNeil DA, Maloff B, Mutasingwa D, Wu M, Ford C and Tough SC. Reducing obesity and related chronic disease risk in children and youth: a synthesis of evidence with 'best practice' recommendations. Obes Rev. 2006; 7 Suppl 1:7-66. | Article | PubMed

5. Merten S, MPH and Julia Dratva, et al. Do baby-friendly hospitals influence breastfeeding duration on a national level?. Pediatrics. 2005; 116:702-708. | Article
6. Abubakari AR, Lauder W, Agyemang C, Jones M, Kirk A and Bhopal RS. Prevalence and time trends in obesity among adult West African populations: a meta-analysis. Obes Rev. 2008; 9:297-311. | Article | PubMed

7. Sattar N, McConnachie A, Shaper AG, Blauw GJ, Buckley BM, de Craen AJ, Ford I, Forouhi NG, Freeman DJ, Jukema JW, Lennon L, Macfarlane PW, Murphy MB, Packard CJ, Stott DJ, Westendorp RG, Whincup PH, Shepherd J and Wannamethee SG. Can metabolic syndrome usefully predict cardiovascular disease and diabetes? Outcome data from two prospective studies. Lancet. 2008; 371:1927-35. | Article | PubMed

8. World Health Organization Controlling the global obesity epidemic. 2008. I Website

9. World Health Organization Global strategy on diet, physical activity and health. 2008. I Pdf

10. Dudeja V, Misra A, Pandey RM, Devina G, Kumar G and Vikram NK. BMI does not accurately predict overweight in Asian Indians in northern India. Br J Nutr. 2001; 86:105-12. | Article | PubMed

11. Appropriate body-mass index for Asian populations and its implications for policy and intervention strategies. Lancet. 2004; 363:157-63. | Article | PubMed

12. Popkin BM. Global nutrition dynamics: the world is shifting rapidly toward a diet linked with noncommunicable diseases. Am J Clin Nutr. 2006; 84:289-98. | Article | PubMed

13. Misra A, Sharma R, Pandey RM and Khanna N. Adverse profile of dietary nutrients, anthropometry and lipids in urban slum dwellers of northern India. Eur J Clin Nutr. 2001; 55:727-34. | Article | PubMed

14. Martorell R, Kettel Khan L, Hughes ML and Grummer-Strawn LM. Overweight and obesity in preschool children from developing countries. Int J Obes Relat Metab Disord. 2000; 24:959-67. | Article | PubMed

15. De Onis $\mathrm{M}$ and Blossner M. Prevalence and trends of overweight among preschool children in developing countries. Am J ClinNutr. 2000; 72:1032-1039. | Article

16. Wang $\mathrm{Y}$, Monteiro $\mathrm{C}$ and Popkin BM. Trends of obesity and underweight in older children and adolescents in the United States, Brazil, China, and Russia. Am J Clin Nutr. 2002; 75:971-7. | Article | PubMed

17. Bhardwaj S, Misra A, Khurana L, Gulati S, Shah P and Vikram NK. Childhood obesity in Asian Indians: a burgeoning cause of insulin resistance, diabetes and sub-clinical inflammation. Asia Pac J Clin Nutr. 2008; 17 Suppl 1:172-5. | Pdf | PubMed

18. Godwin Stewart. Globalization, Education, and Emiratisation: A Study of the United Arab Emirates. EJISDC. 2006 :4. | Article

19. Haslam D. Obesity: a medical history. Obes Rev. 2007; 8 Suppl 1:31-6. | Article | PubMed

20. Caballero B. The global epidemic of obesity: an overview. Epidemiol Rev. 2007; 29:1-5. | Article | PubMed

21. WHO. Obesity and overweight. 2011. | Website

22. Peter G. Kopelman, Ian D. Caterson, Michael J. Stock and William H. Dietz. Clinical obesity in adults and children: In Adults and Children. Blackwell Publishing. 2005.p. 493. I Article

23. Haslam DW and James WP. Obesity. Lancet. 2005; 366:1197-209. | Article I PubMed

24. WHO. Preventing Chronic Disease: A Vital Investment. Geneva: World Health Organisation, 2005. I Pdf

25. Stunkard AJ. Socioeconomic status and obesity. Ciba Found Symp. 1996; 201:174-82. | PubMed

26. Strong K, Mathers C, Leeder S and Beaglehole R. Preventing chronic diseases: how many lives can we save? Lancet. 2005; 366:1578-82. | Article | PubMed

27. Horton R. The neglected epidemic of chronic disease. Lancet. 2005. Article

28. World Health Organization. Technical report series 894: Obesity: Preventing and managing the global epidemic.. Geneva: World Health Organization. | Website

29. World Health Organization. The Asia-Pacific perspective.Redefining 
Ellulu et al. Global Epidemic Obesity 2014,

obesity and its treatment. International Diabetes Institute. Health Communications Australia Pty. Ltd.. 2000. | Pdf

30. WHO. Diet, Nutrition and the Prevention of Chronic Diseases. Report of a Joint WHO/FAO Expert Consultation. WHO Technical Report Series 916. Geneva: World Health Organisation, 2003. | Website

31. Thompson DL. The costs of obesity: what occupational health nurses need to know. AAOHN J. 2007; 55:265-70. | PubMed

32. Popkin BM, Horton S, Kim S, Mahal A and Shuigao J. Trends in diet, nutritional status, and diet-related noncommunicable diseases in China and India: the economic costs of the nutrition transition. Nutr Rev. 2001; 59:379-90. | Article | PubMed

33. Runge CF. Economic consequences of the obese. Diabetes. 2007; 56:2668-72. | Article | PubMed

34. Dalton A and Crowley S. Economic Impact of NCD in the Pacific Islands in obesity in the Pacific: too big to ignore. Based on the outcome of the Workshop on Obesity Prevention and Control Strategies in the Pacific, Samoa, September 2000, convened by the World Health Organization Regional Office for the Western Pacific, in collaboration with the Secretariat of the Pacific Community, the International Obesity Task Force, the United Nations Food and Agriculture Organization and the International Life Sciences Institute. 2002.

35. Zhao W, Zhai Y, Hu J, Wang J, Yang Z, Kong L and Chen C. Economic burden of obesity-related chronic diseases in Mainland China. Obes Rev. 2008; 9 Suppl 1:62-7. | Article | PubMed

36. Wang $L$, Kong $L, W u F$, Bai $Y$ and Burton R. Preventing chronic diseases in China. Lancet. 2005; 366:1821-4. | Article | PubMed

\section{Citation:}

Ellulu M, Abed Y, Rahmat A, Ranneh Y and Ali F. Epidemiology of obesity in developing countries: challenges and prevention. Glob Epidemi Obes.

$2014 ; 2: 2$

http://dx.doi.org/10.7243/2052-5966-2-2 